\title{
On the unacceptable reporting of results in doping control
}

\author{
Klaas Faber
}

Received: 26 March 2009/Published online: 7 May 2009

(c) Springer-Verlag 2009

Sir,

In doping control in sport, the athlete's defense receives only the scarce scientific information the prosecution finds fit for making available. Let us first turn attention to what is actually made available. The latter is laid down in a technical document issued by the World Anti-Doping Agency (WADA) [1]. Apart from fixing numerous details that deal with quality aspects rather than analytical science, e.g., the so-called chain of custody and instrument performance, this document devotes only a single sentence to scientific results reporting concerning the confirmation step, namely:

Identification data and/or quantitative data and uncertainty estimation, if applicable

The addition "if applicable" reads like a legal disclaimer, which is truly horrifying for scientists. Clearly, uncertainty estimation is always applicable in applied analytical work; see e.g., the authoritative editorial by De Bièvre ("Measurement results without statements of reliability (uncertainty) should not be taken seriously") [2]. The following quote from van der Veen's readable account [3] is specifically suited for doping control in sport: "When a laboratory fails to meet the burden of proof, for example by giving a wrong impression of its uncertainty, the conclusion drawn from data obtained in a doping test is disqualified due to the fact that the evidence gathered is grossly incomplete. Failing to provide a correct statement of measurement uncertainty is as much an offense against the applicable rules as is providing a wrong value, or a wrong identification." We therefore insist that it is not up to the laboratory to decide whether uncertainty estimation is applicable or not.

K. Faber $(\bowtie)$

Chemometry Consultancy, Goudenregenstraat 6,

6573 XN Beek-Ubbergen, The Netherlands

e-mail: nmf@chemometry.com
Let us now turn attention to essential information that is actually not made available. We restrict ourselves to:

- Standard operating procedures (SOPs). Without SOPs, how to determine which biases have entered the method, either intentionally or unintentionally? Confirmation bias, for example, is always present, since, unlike the A-sample, the B-sample is not anonymous.

- Validation data. Without these data, how to determine what confidence should be placed in the method?

What can be the justification for these curious omissions? One can only guess from vague statements like "a list of information necessary to support the analytical result". From this particular one, it can safely be inferred that the crucial (logical) distinction between necessary and sufficient is overlooked. Clearly, only the latter is relevant, whereas the former currently leads to a subjective selection at best.

In conclusion, the athlete's defense remains little, apart from protesting on procedural grounds, i.e., mere quality aspects. Much of the analytical science can simply not be questioned since it remains unknown! This malpractice obviously violates fundamental rights of the athlete. Laboratories, as well as their clients and (re-)accrediting organizations, should start reflecting on their accountability for this malpractice.

\section{References}

1. World Anti-Doping Agency (2009) Laboratory documentation packages, Version 1.0. http://www.wada-ama.org/rtecontent/document/ LABORATORY_DOCUMENTATION_PACKAGES_TD_v1_0_ January_2009.pdf

2. De Bièvre P (1997) Accred Qual Assur 2:269. doi:10.1007/ s007690050147

3. Van der Veen AMH (2003) Accred Qual Assur 8:334-339. doi: 10.1007/s00769-003-0644-6 